Article

\title{
Solid-State Membrane Sensors Based on Man-Tailored Biomimetic Receptors for Selective Recognition of Isoproturon and Diuron Herbicides
}

\author{
Ayman H. Kamel ${ }^{1, *(1)}$, Abd El-Galil E. Amr ${ }^{2,3, *\left(\mathbb{C}, \text { Mohamed A. Al-Omar }^{2}(\mathbb{D} \text { and }\right.}$ \\ Abdulrahman A. Almehizia ${ }^{2}$ D \\ 1 Department of Chemistry, Faculty of Science, Ain Shams University, Cairo 11566, Egypt \\ 2 Pharmaceutical Chemistry Department, Drug Exploration \& Development Chair (DEDC), \\ College of Pharmacy, King Saud University, Riyadh 11451, Saudi Arabia; \\ malomar1@ksu.edu.sa (M.A.A.-O.); mehizia@ksu.edu.sa (A.A.A.) \\ 3 Applied Organic Chemistry Department, National Research Center, Dokki 12622, Giza, Egypt \\ * Correspondence: ahkamel76@sci.asu.edu.eg (A.H.K.); aamr@ksu.edu.sa (A.E.-G.E.A.); \\ Tel.: +20-1000361328 (A.H.K.); +966-565-148-750 (A.E.-G.E.A.)
}

Received: 15 September 2020; Accepted: 6 October 2020; Published: 12 October 2020

\begin{abstract}
Solid-contact ion-selective electrodes (SC-ISEs) have shown great potential for routine and portable ion detection. The introduction of nanomaterials as ion-to-electron transducers and the adoption of different performance-enhancement strategies have significantly promoted the development of SC-ISEs. Herein, new solid-contact ion-selective electrodes, along with the implementation of multiwalled carbon nanotubes (MWCNTs) as ion-to-electron transducers and potassium tetrakis (p-chlorophenyl) borate $(\mathrm{KTpClB})$ as lipophilic ionic additives, were presented for the detection of isoproturon (IPU) and diuron (DU) herbicides. Molecularly imprinted polymers (MIPs), with special molecule recognition properties for isoproturon (IPU) and diuron (DU), were prepared, characterized, and introduced as sensory recognition materials in the presented electrodes. Sensors revealed a near-Nernstian response for both isoproturon (IPU) and diuron (DU) with slopes of $53.1 \pm 1.2\left(r^{2}=0.997\right)$ and $57.2 \pm 0.3\left(r^{2}=0.998\right)$ over the linear ranges of $2.2 \times 10^{-6}-1.0 \times 10^{-3} \mathrm{M}$ and $3.2 \times 10^{-6}-1.0 \times 10^{-3} \mathrm{M}$ with detection limits of $8.3 \times 10^{-7}$ and $1.4 \times 10^{-6} \mathrm{M}$, respectively. The response time of the presented sensors was found to be $<5 \mathrm{~s}$ and the lifetime was at least eight weeks. The sensors exhibited good selectivity towards isoproturon (IPU) and diuron (DU) in comparison with some other herbicides, alkali, alkaline earth, and heavy metal ions. The presented sensors were successfully applied for the direct determination of isoproturon (IPU) and diuron (DU) in real water samples.
\end{abstract}

Keywords: phenylurea herbicides; isoproturon; diuron; solid-contact; potentiometric sensors; molecularly imprinted polymers (MIPs)

\section{Introduction}

Herbicides account for about 50\% of agrochemical demand. The danger of these chemicals lies in their prolonged use and the risks of their presence in crops and soil. These materials are transferred to surface water and groundwater due to the washing and leaching operations of agricultural soil [1]. Phenylurea herbicides are selective herbicides that are commonly used in agriculture, either alone or in combination with other pesticides, to treat soil before emergence. Due to their polar nature, potential leakage from the surface into water supplies and water reserves, together with the emergence of the potentially toxic degradation and metabolic products, poses a risk to human health [2,3]. Duron is considered to be a persistent toxic herbicide in the phenylurea herbicide family. The European 
Commission has listed it as a priority hazardous substance. Its half-life is more than 300 days, so its survival in soil without decomposition is a dangerous reservoir, especially as it is used to control emergency situations in crop and noncrop areas [4]. Diuron has high persistence as well as genotoxicity, so there are many reported strategies aimed to provide its uptake and degradation in various ways [5]. Isoproturon also belongs to the family of phenylurea pesticides, which exhibit similar properties such as stability, persistence, and solubility in water. The uncontrolled use of these dangerous compounds poses a severe risk to the environment as well as aquatic organisms. This raises major concerns due to their slow biodegradation and their genetic and environmental toxicity [6].

Various analytical techniques have been indexed for the determination of different phenylurea compounds [7-12]. These reported methods required complex procedures and nonportable equipment. In addition, they need prior derivatization or extraction steps and involve expensive equipment and chemicals. All of these drawbacks do not enable the use of such methods in the routine analysis of such herbicides.

Among these techniques, electrochemical methods can be very attractive because of their fast response, low cost, high selectivity, suitability for on-site analysis, and reproducibility [13,14]. Moreover, these techniques can allow multicomponent quantification, resulting in rapid analysis that is time-saving and has an economic return and advantages. The few reported works available in the literature have been monitored on the basis of the electrochemical determination of phenylurea herbicides [15-18]. Among all electrochemical techniques, potential-based transduction "potentiometry" is potentially the most preferred technique. It presents good advantages such as quick and analysis, high sensitivity, cost-effectiveness, simplicity in use, and response reliability [19-21].

Solid-contact potentiometric sensors, especially, are considered attractive devices for a very wide range of practical applications [22-25]. In comparison with liquid-contact electrodes, solid-contact sensors are cost-effective, simpler to use and transport, and more mechanically resistant. Moreover, they are pressure resistant, can work in any position, are easy to back and seal, and allow miniaturization for portable devices. Unfortunately, direct contact between the electronic conductors and the ion-sensing membranes (ISM) leads to a large potential deviation due to the high resistance of the charge transfer [26]. To overcome these problems, an intermediate layer of conductive polymers or nanomaterials with mixed ion and electronic conductivity should be inserted between the ISM and the electronic conductor [27]. This intermediate layer should be hydrophobic to prevent the formation of a water layer on the interface and be resistant to the effects of $\mathrm{CO}_{2}, \mathrm{pH}$, or light sensitivity $[28,29]$.

For years, molecular imprinting technology has been a successful tool for preparing polymeric materials characterized by their high selectivity and affinity. The synthesis of molecularly imprinted polymers (MIPs) involves the assembly of monomers around a template molecule, followed by polymerization in the presence of a cross-linker and initiator. After template removal, specific sites for this template molecule are found with respect to both shape and chemical function, allowing for subsequent recognition of the template. Such synthetic receptors are characterized by their physical durability, high strength, resistance to high temperatures and pressure, and high stability with acids, bases, metal ions, and organic solvents. MIPs have been used in a wide variety of applications. These applications include catalysis processes [30], identification and determination of toxins in food matrices [31,32], solid-phase extraction (SPE) [33], drug delivery [34,35], biological antibody and receptor systems [36,37], and chemical sensor devices [38-40].

The integration of MIPs into potentiometric electrodes provide good features such as high selectivity and sensitivity, low detection limits, as well as easy miniaturization and automation. These synthetic receptors have been extensively used to quantify various organic and inorganic ions [41-46]. Until now, no potentiometric sensors for the determination of either isoproturon or diuron herbicides have been reported.

In the present work, we describe, for the first time, sensitive potentiometric sensors for the determination of isoproturon and diuron herbicides. The sensors are based on the dispersion of artificially imprinted receptors for these templates in 2-nitrophenyloctyl ether (o-NPOE) and 
embedded in a polyvinyl chloride (PVC) matrix. MWCNTs were used as solid-contact transducers and potassium tetrakis (p-chlorophenyl) borate $(\mathrm{KTpClB})$ as a lipophilic ionic additive. The electrochemical performance characteristics of the proposed electrodes were evaluated for the simple, fast, selective, and cost-effective analysis of diuron and isoproturon in different wastewater samples collected from agricultural resources.

\section{Experimental}

\subsection{Equipment}

All potentiometric measurements were performed at room temperature $\left(25 \pm 1^{\circ} \mathrm{C}\right)$ using a digital $\mathrm{pH} / \mathrm{mV}$ meter (PXSJ-216, INESA Scientific Instrument Co., Ltd, Shanghai, China). An Ag/AgCl/KCl (3 M) double-junction reference electrode (Orion 90-02) filled with $0.1 \mathrm{M} \mathrm{CH}_{3} \mathrm{COOLi}$ in its outer compartment was used in conjunction with the proposed ion-selective electrode (ISE) to construct the electrochemical cell. A combined glass/pH electrode (Orion 81-02) was used for all $\mathrm{pH}$ measurements. The Milli-Q PLUS reagent-grade water system (Millipore, Burlington, MA, USA) (18.2 M $2 \cdot \mathrm{cm}$ specific resistance) was used for obtaining deionized water. Glassy carbon (GC) rods $3 \mathrm{~mm}$ in diameter were supplied from HTW GmbH. All spectrophotometric measurements were carried out using the Shimadzu UV-1601 (PC, Osaka, Japan) spectrophotometer. The controlled three-electrode system was used for all chronopotentiometric and impedance measurements. The cell assembly included a Pt wire as an auxiliary, and a single-junction $\mathrm{Ag} / \mathrm{AgCl}(3 \mathrm{M}) \mathrm{KCl}$ as a reference electrode.

\subsection{Reagents and Materials}

All reagents were of analytical grade and used as received without further purification. High-molecular-weight polyvinyl chloride (PVC), tetrahydrofuran (THF), potassium tetrakis (p-chlorophenyl) borate (KTpClB), multiwalled carbon nanotubes (MWCNTs, >95\% purity) with 6-9 $\mathrm{nm}$ in diameter and $5 \mu \mathrm{m}$ in length, tetradodecylammonium tetrakis (4-chlorophenyl) borate (ETH500), and o-nitrophenyl octyl ether (o-NPOE) were obtained from Sigma-Aldrich (St. Louis, MO, USA). Methacrylic acid (MAA), ethylene glycol dimethacrylate (EGDMA), and benzoyl peroxide (BPO) were obtained from Fluka (Ronkonkoma, NY). Isoproturon (IPU) and diuron (DU) (see Figure 1 for chemical structures) were obtained from Riedel-de Haën (Seelze, Germany).

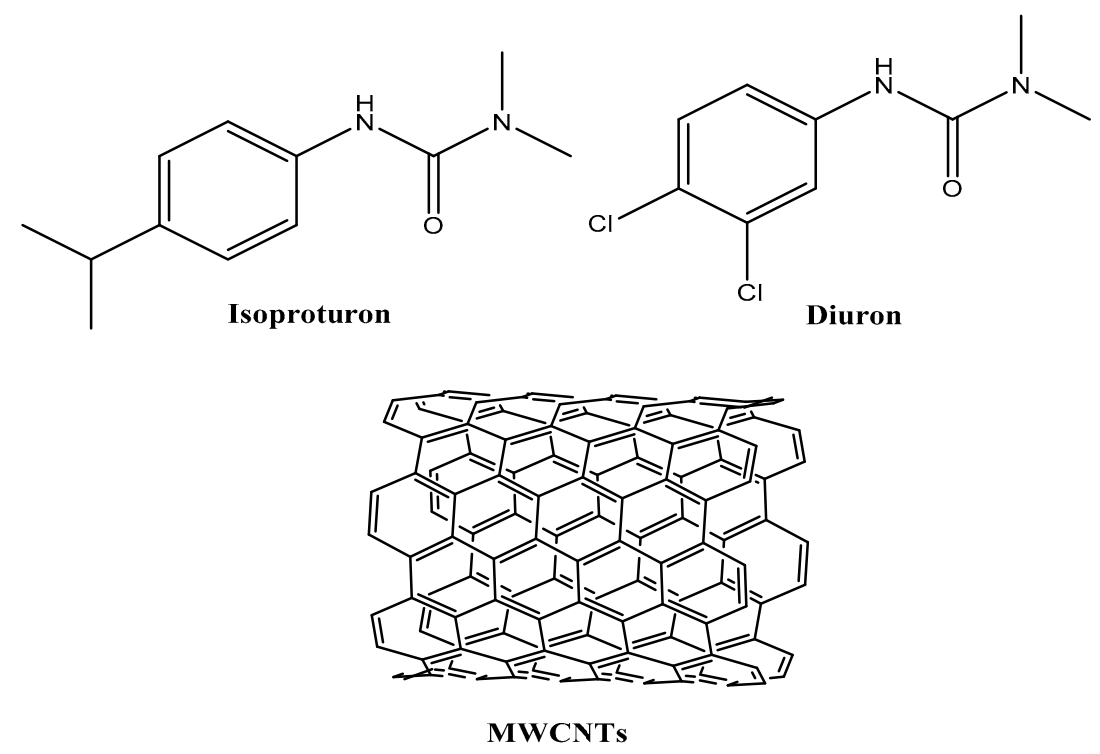

Figure 1. Chemical structure of the studied compounds. 
The herbicide stock solutions $\left(10^{-3} \mathrm{M}\right)$ were prepared by dissolving an appropriate amount of the compound in methanolic solution and kept in the dark at $-5{ }^{\circ} \mathrm{C}$. Working solutions were prepared daily by diluting the stock solution with Britton-Robinson (BR) buffer (0.04 M boric acid, $0.04 \mathrm{M}$ phosphoric acid, and $0.04 \mathrm{M}$ acetic acid). The $\mathrm{pH}$ was adjusted with $0.2 \mathrm{M} \mathrm{NaOH}$, covering the $\mathrm{pH}$ range from 2.0 to 7.0 .

\subsection{Synthesis of Host-Tailored Polymers}

For the preparation of MIPs, $0.5 \mathrm{mmol}$ of the template (either isoproturon or diuron) was mixed with $3.0 \mathrm{mmol}$ of the functional monomer MAA in a glass tube and left for $1 \mathrm{~h}$. Then, $3.0 \mathrm{mmol}$ of the cross-linker EGDMA was added to the mixture followed by $0.3 \mathrm{mmol}$ of the initiator BPO. All components were mixed together with $15 \mathrm{~mL}$ acetonitrile. Following this, the mixture was sonicated for 10 min until complete dissolution. The reaction mixture was degassed with $\mathrm{N}_{2}$ gas for 15 min, and placed in an oil bath for $18 \mathrm{~h}$ at $70{ }^{\circ} \mathrm{C}$. The obtained polymeric beads were ground and washed with methanol to remove all unreacted species. Extraction of the template molecule was carried out via soxhlet using methanol/acetic acid $(8: 2, v / v)$. For complete removal of the template molecule from the MIP skeleton, the washing solution was measured spectrophotometrically at $\lambda_{\text {max }}=245$ and $250 \mathrm{~nm}$ to check the existence of either isoproturon or diuron, respectively. The particles were repeatedly washed until the herbicide was no longer detected. The resulting polymeric beads were left to dry at room temperature prior to use. Nonimprinted polymers (NIPs) were synthesized in a similar way as mentioned above with the exclusion of the template from the procedure.

\subsection{Binding Experiments}

Binding experiments were performed by inserting $20.0 \mathrm{mg}$ of either MIP or NIP beads in contact with $10.0 \mathrm{~mL}$ of either IPU or DU solutions in the concentration range of $0.02-0.5 \mathrm{mM}$. The heterogeneous mixture was shaken for $12 \mathrm{~h}$ at an ambient temperature followed by centrifugation $(3000 \times g \mathrm{rpm}$, $10 \mathrm{~min}$ ) for solid-phase separation. The remaining concentration of the herbicide in the supernatant solution was determined using UV spectrophotometry measurements at the wavelength corresponding to the herbicide detected. The amount of each herbicide bound to the polymeric beads was evaluated after subtracting the free herbicide concentration from its initial value.

\subsection{Sensor Preparation}

Glassy carbon (GC) disks with a diameter of $3 \mathrm{~mm}$ and a height of $5 \mathrm{~mm}$ were used as electronic conductors for solid-contact ISEs. The GC disks were carefully polished with $0.3 \mu \mathrm{m} \mathrm{Al}_{2} \mathrm{O}_{3}$ slurries, sonicated in ethanol for $15 \mathrm{~min}$, and rinsed with water. The disks were washed with ethanol and dried in air. A piece of matched PVC tube $(1 \mathrm{~cm}$ long, $5 \mathrm{~mm}$ i.d., and $8 \mathrm{~mm}$ o.d.) was tightly inserted at the distal end of the electrodes. The ISM cocktail (total mass of $112 \mathrm{mg}$ in $2.0 \mathrm{~mL}$ THF) was prepared after dispersing MIP or NIP particles (12 mg), KTpClB (1.0 mg), ETH 500 (1 mg), o-NPOE (49.0 mg), and PVC (49.0 mg) together with $1 \mathrm{mg} / \mathrm{mL}$ of the MWCNTs in THF. The mixture was sonicated for 30 min until a uniform solution was obtained. A $100 \mu \mathrm{L}$ volume of the membrane cocktail covered the GC disks via drop-casting, and the solvent was left to be evaporated overnight at room temperature. A uniform composite layer was obtained and strongly adhered to the GC surface. The coated-wire electrodes (CWEs) were also prepared by the same steps as mentioned above but without the addition of a MWCNT layer. All solid-contact-selective electrodes were, firstly, conditioned in $10^{-4} \mathrm{M}$ of either IPU or DU solutions for 1 day; then, they were conditioned in $10^{-8} \mathrm{M}$ of IPU or DU solutions for 2 days. A $50 \mathrm{mM}$ BR buffer ( $\mathrm{pH}=3$ ) was used to adjust the $\mathrm{pH}$ of all working solutions.

\subsection{Analytical Applications}

Agriculture wastewater samples were collected from different areas in Giza, Egypt. The samples were degassed in an ultrasonic bath. A $10 \mathrm{~mL}$ volume of the sample solution was spiked with different aliquots of IPU and DU within a concentration range of $0.5-10.0 \mu \mathrm{g} / \mathrm{mL}$. The working sensors, in 
conjunction with the reference electrode, were immersed in the test solution. The potential reading was recorded and the concentration of the test solution was determined from the constructed calibration plot.

\section{Results and Discussion}

Herein, we aimed to present a fast, simple, reliable, and sensitive method of analysis based on MIPs for detecting isoproturon and diuron as phenylurea herbicides. For this purpose, we presented a solid-contact potentiometric sensor utilizing MWCNTs as ion-to-electron transducers. A schematic illustration for the proposed mechanism of transduction is shown in Figure 2.

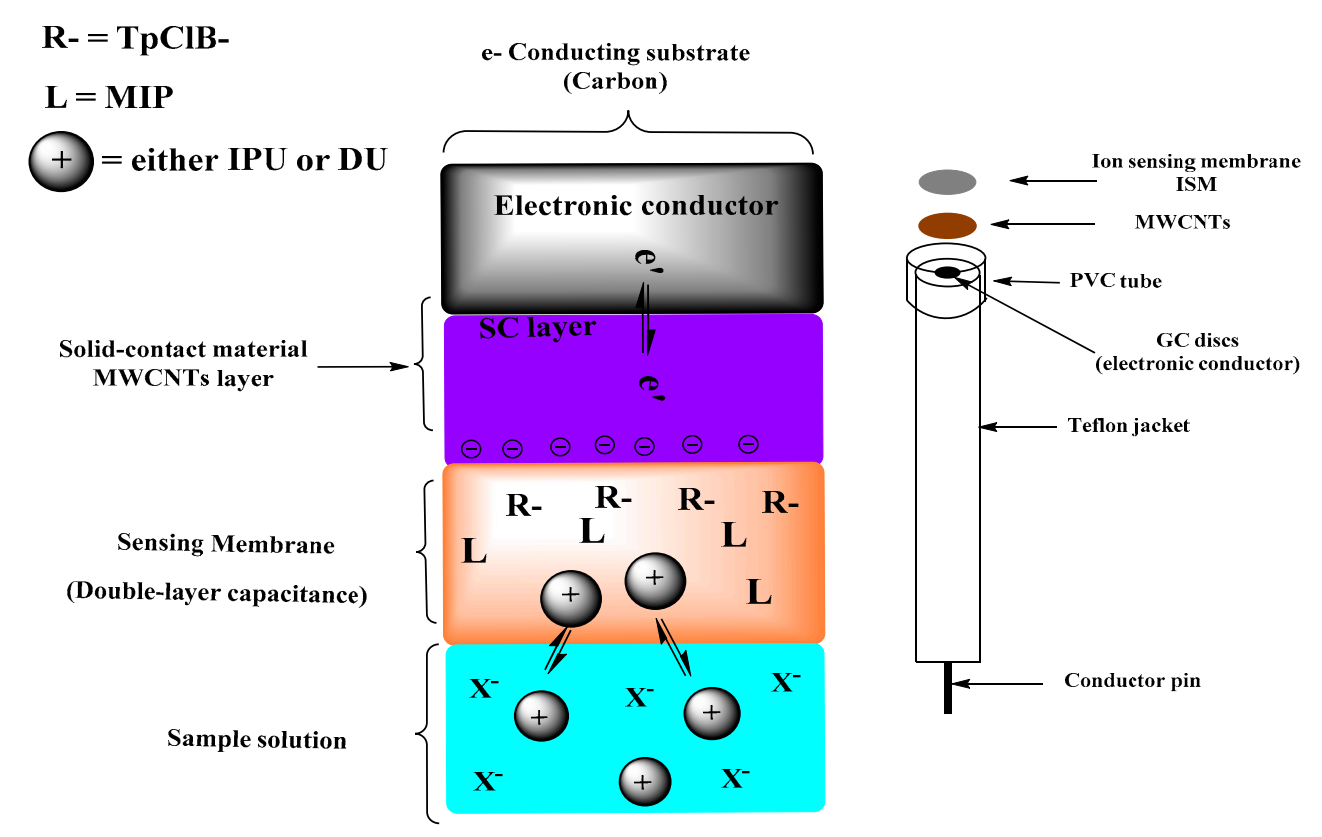

Figure 2. Response mechanism of the proposed solid-contact ion-selective electrodes (ISEs).

\subsection{Equilibrium Adsorption}

Adsorption isotherms are an important tool to explain how small molecules can interact with the surfaces of adsorbents. In these isotherms, the concentration at the equilibrium of the bound adsorbate is plotted versus the free adsorbate concentration. In liquid-phase applications of MIPs, the adsorbate molecules interact with the binding sites in the solid-adsorbent MIP. After equilibrium is attained, the constant-free adsorbate concentration can be determined to construct the corresponding adsorption isotherm [47]. The static equilibrium adsorption experiments for the synthesized MIPs were performed using $0.02-0.5 \mathrm{mM}$ as an initial concentration of either IPU or DU herbicides. The obtained adsorption isotherms are shown in Figure 3a. It was noticed that the ability of MIPs to adsorb their corresponding herbicide increases as the initial concentration of the herbicide increases. The adsorbitivity of the NIPs reached a saturation state for all tested herbicides when the initial concentration of the herbicide was beyond $0.08 \mathrm{mM}$. It was found that the binding affinity of MIPs towards either IPU or DU herbicides was bigger than that of the NIP beads. This can confirm the existence of selective active sites with a high affinity and specific recognition on MIPs. 

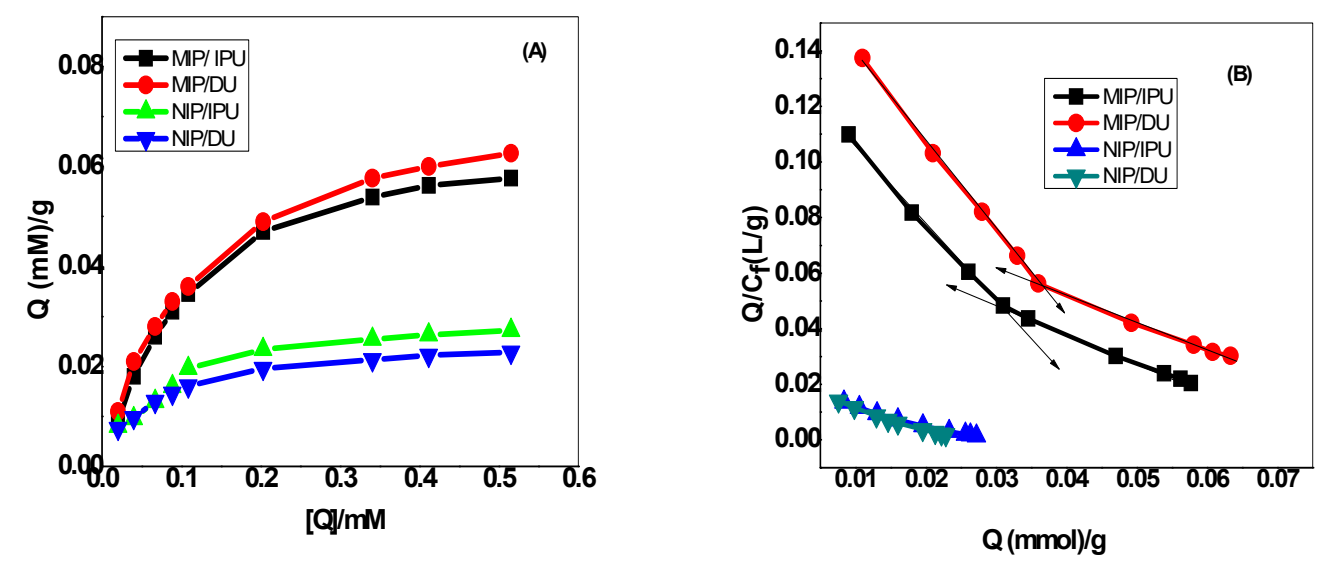

Figure 3. Binding isotherm (A) and Scatchard plot (B) for both isoproturon (IPU)- and diuron (DU)-imprinted polymers. $Q=$ herbicide bound to $20.0 \mathrm{mg}$ of the corresponding polymer; temperature $=25^{\circ} \mathrm{C}$; volume $=10.0 \mathrm{~mL}$; binding time $=12 \mathrm{~h}$.

The Scatchard model was used to evaluate the binding characteristics of either MIPs or NIPs. The Scatchard equation can be described as [47]:

$$
[Q] /\left[C_{f}\right]=\left(\left[Q_{\max }\right]-[Q]\right) / K_{d}
$$

where $K_{d}$ is the dissociation constant, $Q_{\max }$ is the maximum binding capacity, and $\left[C_{f}\right]$ is the equilibrium-free concentration of the substrate in the supernatant. As mentioned in Figure $3 b$, the binding sites of the prepared MIPs were heterogeneous. This can conclude the existence of two binding site classes with different affinities in the range of the different concentrations. This can be attributed to the presence of various modes of interaction between the template molecule and the functional monomer. These modes of interaction can form different kinds of complexes with different components that lead to the formation of different binding sites with different properties after polymerization. The two sections of the linear plot in Figure $3 \mathrm{~b}$ can fit the data. At the higher-affinity binding sites, the dissociation constant $K_{d 1}$ and the apparent maximum amount $Q_{\max 1}$ were found to be 0.344 and $0.31 \mathrm{mM}$ and 0.046 and $0.053 \mathrm{mmol} / \mathrm{g}$ for MIP/IPU and MIP/DU, respectively. By the same treatment, $K_{d 2}$ and $Q_{\max 2}$ for the lower-affinity binding sites were calculated to be 0.969 and $1.036 \mathrm{mM}$ and 0.077 and $0.093 \mathrm{mmol} / \mathrm{g}$ for MIP/IPU and MIP/DU, respectively. In contrast, the $K_{d}$ and $Q_{\max }$ values were found to be 1.583 and $1.288 \mathrm{mM}$ and 0.028 and $0.0245 \mathrm{mmol} / \mathrm{g}$ for NIP/IPU and $\mathrm{NIP} / \mathrm{DU}$, respectively. This indicates a high homogeneity of the binding sites present in NIP beads and shows a lower affinity towards the studied phenylurea herbicides than their corresponding MIPs.

\subsection{Surface Morphology}

The surface morphologies of both NIPs and MIPs after template removal were also examined and shown in the SEM micrographs (Figure 4). For MIPs, the beads were semispherical with an irregular shape and had a size ranging between 0.8 and 1.1 and 0.65 and $0.95 \mu \mathrm{m}$ for both MIP/IPU (Figure 4a) and MIP/DU (Figure 4b), respectively. For NIPs, it was found that the beads were spherical, smooth, and uniformly shaped, with a size ranging between 1 and $2 \mu \mathrm{m}$, as mentioned in Figure $4 \mathrm{c}$. This can be attributed to the absence of specific binding sites in the polymers. These morphological differences can confirm the presence of the imprinting process and the ability of MIPs to adsorb and uptake these phenylurea herbicides more than NIP beads. 


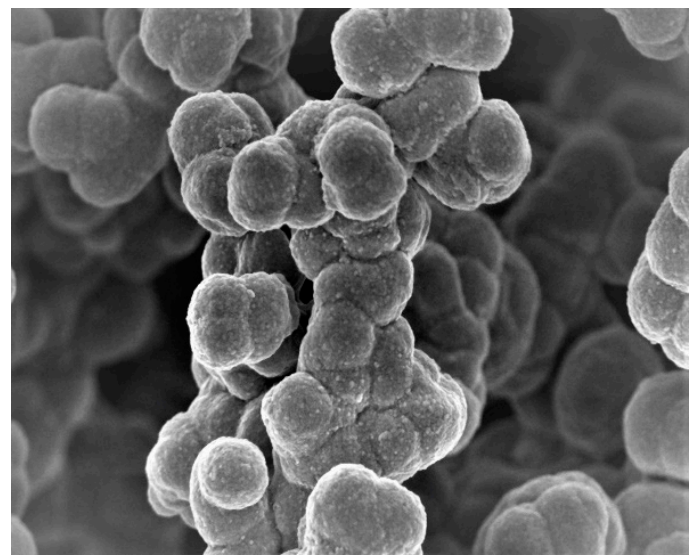

(a)

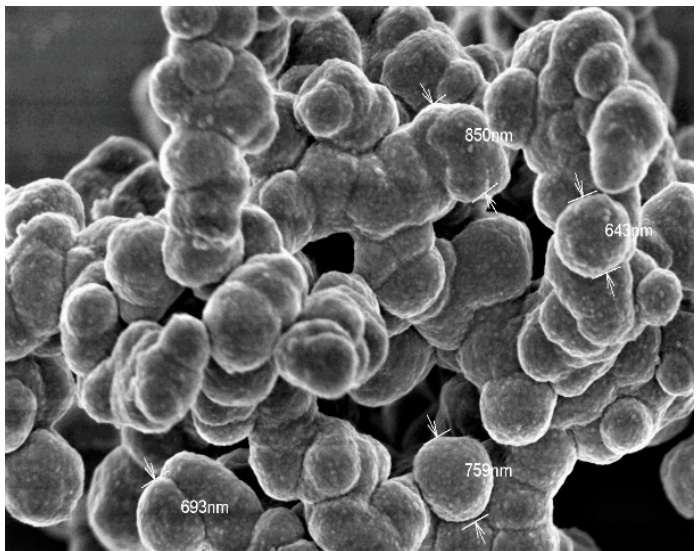

(b)

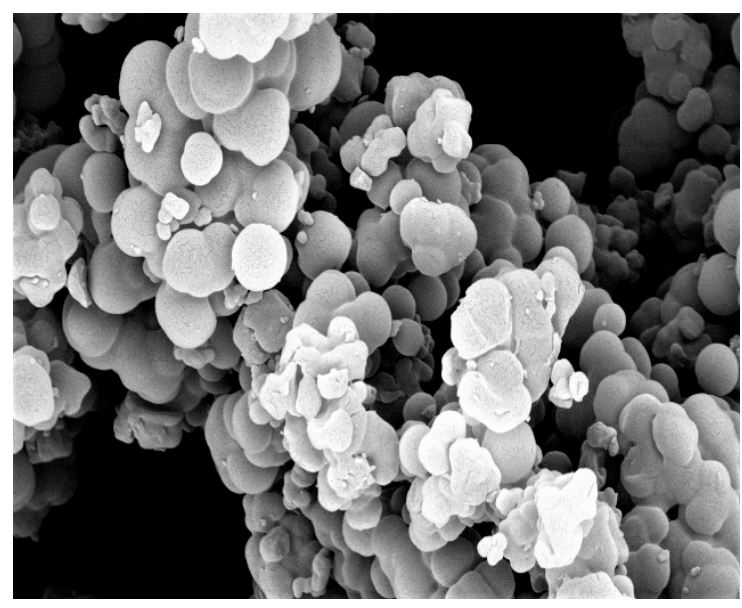

(c)

Figure 4. SEM images of (a) molecularly imprinted polymers (MIP)/IPU, (b) MIP/DU, and (c) nonimprinted polymer (NIP) beads. Conditions: scale bar $=2.00 \mu \mathrm{m}, 3.0 \mathrm{kv} ; 27 \mathrm{~mm} \times 20.0 \mathrm{kv}$.

\subsection{ISE Performance Characteristics}

The prepared MIPs were dispersed and introduced as sensing materials into a plasticized PVC membrane in the presence of the anionic additive $\mathrm{KTpClB}$ to prepare the presented electrodes.

The potential-log [concentration] plots for MIP/IPU (Sensor 1) and MIP/DU (Sensor 2) are shown in Figure 5. The sensors exhibited a linear potentiometric response over the ranges of $2.2 \times 10^{-6}-1.0$ $\times 10^{-3} \mathrm{M}$ and $3.2 \times 10^{-6}-1.0 \times 10^{-3} \mathrm{M}$ with detection limits of $8.3 \times 10^{-7}$ and $1.4 \times 10^{-6} \mathrm{M}$ and near-Nernstian slopes of $53.1 \pm 1.2\left(r^{2}=0.997\right)$ and $57.2 \pm 0.3\left(r^{2}=0.998\right) \mathrm{mV} /$ decade for Sensors 1 and 2, respectively. Sensors based on NIPs (i.e., NIP/IPU (Sensor 3) and NIP/DU (Sensor 4) exhibited a linear potentiometric response within the ranges of $3.2 \times 10^{-5}-1.0 \times 10^{-3}$ and $3.4 \times 10^{-5}-1.0 \times 10^{-3} \mathrm{M}$ with detection limits of $1.3 \times 10^{-5}$ and $1.2 \times 10^{-5} \mathrm{M}$ and sub-Nernstian slopes of $39.8 \pm 0.7\left(r^{2}=0.999\right)$ and $47.2 \pm 0.9\left(r^{2}=0.998\right)$, for Sensors 3 and 4 , respectively. The performance characteristics of the presented sensors were shown in Table 1. 


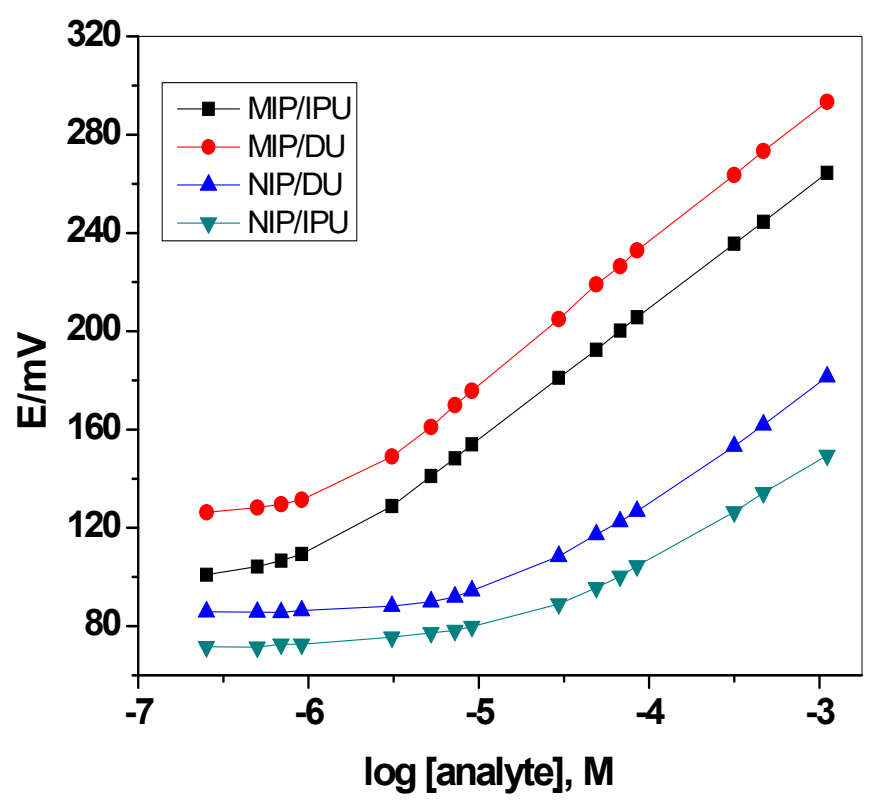

Figure 5. Calibration plots for all solid-contact ISEs in the Britton-Robinson (BR) buffer solution ( $\mathrm{pH}=3.0$ ).

Table 1. Potentiometric response characteristics of phenylureas sensors.

\begin{tabular}{ccccc}
\hline Parameter & $\begin{array}{c}\text { MIP(IPU)/MWCNTs-ISEs } \\
\text { (Sensor 1) }\end{array}$ & $\begin{array}{c}\text { MIP(DU)/MWCNTs-ISEs } \\
\text { (Sensor 2) }\end{array}$ & $\begin{array}{c}\text { NIP/IPU } \\
\text { (Sensor 3) }\end{array}$ & $\begin{array}{c}\text { NIP/DU } \\
\text { (Sensor 4) }\end{array}$ \\
\hline Slope, mV/decade & $53.1 \pm 1.2$ & $57.2 \pm 1.2$ & $39.8 \pm 0.9$ & $48.1 \pm 0.6$ \\
Correlation & 0.997 & 0.998 & 0.998 & 0.998 \\
coefficient, $\mathrm{r}^{2}$ & $2.2 \times 10^{-6}-1.0 \times 10^{-3}$ & $3.2 \times 10^{-6}-1.0 \times 10^{-3}$ & $3.2 \times 10^{-5}-1.0 \times 10^{-3}$ & $3.4 \times 10^{-5}-1.0 \times 10^{-3}$ \\
Linear range, $\mathrm{M}$ & $8.3 \times 10^{-7}$ & $1.4 \times 10^{-6}$ & $1.3 \times 10^{-5}$ & $1.2 \times 10^{-5}$ \\
Detection limit, $\mathrm{M}$ & $2.5-4.5$ & $2.5-4.5$ & $2.5-4.5$ & $2.5-4.5$ \\
Working range, $\mathrm{pH}$ & $<10$ & $<10$ & $<10$ & $<10$ \\
Response time, s & 1.1 & 0.7 & 1.2 & 0.9 \\
Standard deviation & 99.1 & 98.8 & 97.6 & 96.8 \\
( $\left.\sigma_{\mathrm{v}}\right), \mathrm{mV}$ & 0.6 & 0.8 & 0.6 & 0.5 \\
Accuracy, $\%$ & 1.1 & 0.9 & 0.8 & 1.2 \\
Precision $\left(\mathrm{CV} \mathrm{w}_{\mathrm{w}}\right), \%$ & & & \\
Between-day & & & & \\
variability $\left(\mathrm{CV}_{\mathrm{b}}\right), \%$ & & & & \\
\hline
\end{tabular}

To test method repeatability, the spread of results obtained for the concentration of either IPU or DU herbicides (i.e., $10 \mu \mathrm{g} / \mathrm{mL}$ ) when measured within-day and between-days under different method conditions and sensor assemblies were calculated. The within-day data repeatability was found to be $0.6 \%$ and $0.8 \%$, while between-day variability was found to be $1.1 \%$ and $0.9 \%$ for Sensors 1 and 2 , respectively.

The standard deviations $\left(\sigma_{\mathrm{v}}\right)$ of the measured potential $(n=5)$ were found to be 1.1 and $0.7 \mathrm{mV}$ for the test solution of $0.1 \mathrm{mM}$ for Sensors 1 and 2, respectively. It was found that the performance response characteristics of the electrodes did not record a remarkable change after the use of the presented electrodes for eight weeks. The validity of the proposed potentiometric method for determining each herbicide was evaluated after determining the range of linearity, detection limit, accuracy (recovery), within-day repeatability (precision, $\left.\mathrm{Cv}_{\mathrm{w}}\right)$, between-day variability $\left(\mathrm{Cv}_{\mathrm{b}}\right)$, and sensitivity in terms of slope [48]. All data obtained were of six batches of each herbicide solution and were shown in Table 1.

The influence of the $\mathrm{pH}$ on the potential response of the proposed sensors was tested using $10^{-4}$ $\mathrm{M}$ of the corresponding herbicide over the $\mathrm{pH}$ range of 2-10 (Figure 6). The adjustment of the $\mathrm{pH}$ of each solution was done using $\mathrm{NaOH}$. The $\mathrm{pH}$ potential plots showed that the electrodes displayed constant potential readings over the $\mathrm{pH}$ range 2.5-4.5 for all presented sensors. A $50 \mathrm{mM} \mathrm{BR}$ buffer at $\mathrm{pH} 3$ was used for all herbicide measurements. 


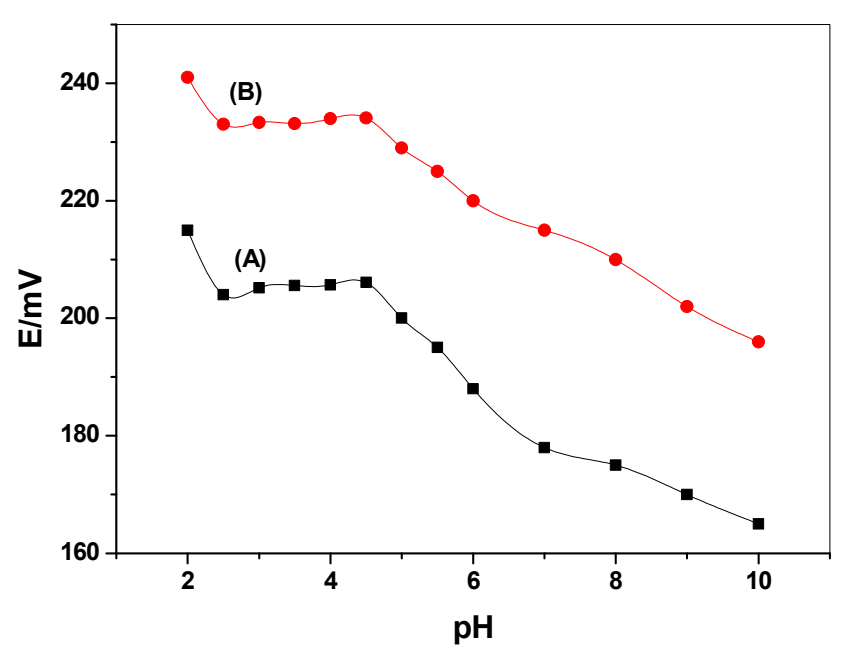

Figure 6. $\mathrm{pH}$ plot for (A) MIP(IPU)/multiwalled carbon nanotubes (MWCNTs)-ISEs and (B) MIP(DU)/MWCNTs-ISEs.

The time taken by the sensors to reach a steady-state potential within $\pm 0.8 \mathrm{mV}$ of the final equilibrium value was recorded after the successive immersion of the electrodes in a series of their corresponding herbicide solutions. Each had 10-fold differences, from low to high concentrations. The response time was $<10 \mathrm{~s}$ for all herbicide solutions of concentrations in the linear range of calibration curves indicating the fast response of the electrodes (Figure 7).

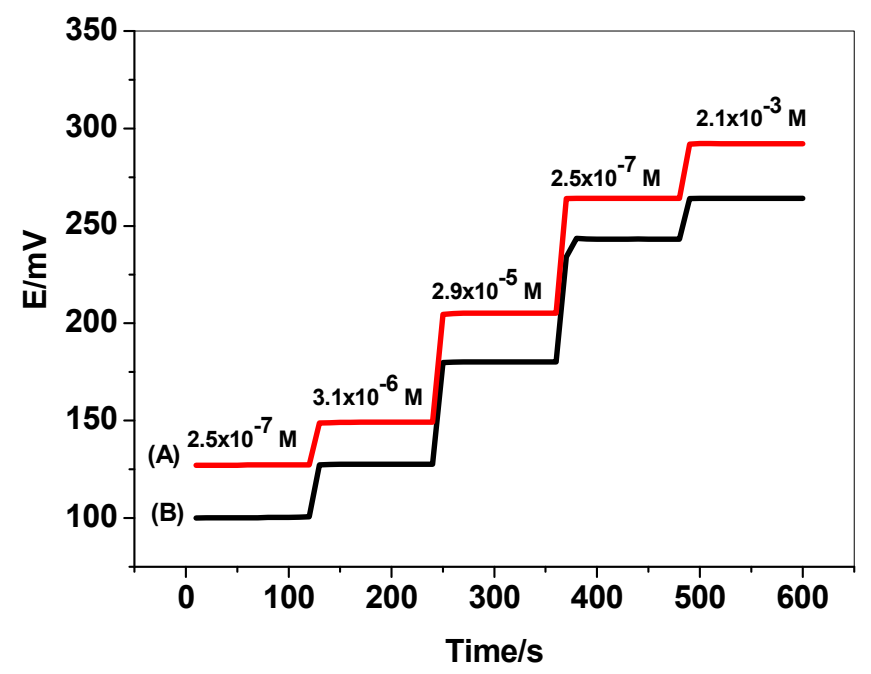

Figure 7. Time response for (A) MIP(IPU)/MWCNTs-ISEs and (B) MIP(DU)/MWCNTs-ISEs.

\subsection{Sensors' Selectivity}

The selectivity behavior of the presented ISEs was evaluated using a modified separate solution method (MSSM) [49]. In brief, the electrodes were subjected to the less-discriminated ion. The potential at $a_{\text {ion }}=1 \mathrm{M}$ was recorded from the extrapolation of the calibration plot of each interfering ion. The selectivity coefficient values were calculated for all sensors and are summarized in Table 2. The typical selectivity order of MIP/IPU- and MIP/DU-based sensors with a membrane plasticized with $o$-NPOE was: IPU $>\mathrm{MU}>\mathrm{FU}>\mathrm{LU}>\mathrm{DU}>$ phenyl urea $>$ phenylalanine $>$ urea $>\mathrm{NH}_{4}{ }^{+}>\mathrm{K}^{+}>$ $\mathrm{Na}^{+}>\mathrm{Ca}^{2+}$ and $\mathrm{DU} \sim \mathrm{LU}>\mathrm{FU}>\mathrm{MU}>\mathrm{IPU}>$ phenyl urea $>$ phenylalanine $>$ urea $>\mathrm{NH}_{4}^{+}>\mathrm{Na}^{+}>$ $\mathrm{K}^{+}>\mathrm{Ca}^{2+}$, respectively. The selectivity pattern in ISEs strongly depended on the recognition affinity of the ligand to the analyte under study. Therefore, the obtained selectivity order of the synthesized 
MIPs suggests that the mechanism of selectivity is mainly governed by stereo-specific and electrostatic aspects, where the lipophilic environment is dictated by the plasticizer.

Table 2. Potentiometric selectivity coefficients $\left(\log K^{p o t}{ }_{i, B}\right)$ of phenylureas PVC membrane sensors.

\begin{tabular}{ccccc}
\hline Interfering Ion, B & MIP (DU)/MWCNTs-ISEs & MIP(IPU)/MWCNTs-ISEs & NIP/DU & NIP/IPU \\
\hline Isoproturon (IPU) & 0 & $-3.1 \pm 0.6$ & 0 & $-3.3 \pm 0.2$ \\
Diuron (DU) & $-3.3 \pm 0.6$ & 0 & $-3.0 \pm 0.1$ & 0 \\
Linuron (LU) & $-2.9 \pm 0.4$ & $-0.7 \pm 0.03$ & $-1.7 \pm 0.3$ & $-1.4 \pm 0.1$ \\
Fenuron (FU) & $-2.8 \pm 0.2$ & $-2.2 \pm 0.6$ & $-1.8 \pm 0.2$ & $-1.7 \pm 0.2$ \\
Methiuron (MU) & $-2.7 \pm 0.7$ & $-2.9 \pm 0.5$ & $-2.0 \pm 0.4$ & $-2.8 \pm 0.4$ \\
Phenylurea & $-3.4 \pm 0.6$ & $-3.5 \pm 0.3$ & $-2.4 \pm 0.2$ & $-2.6 \pm 0.4$ \\
Phenylalanine & $-4.7 \pm 0.8$ & $-4.6 \pm 0.9$ & $-3.1 \pm 0.3$ & $-3.8 \pm 0.2$ \\
Urea & $-5.1 \pm 0.2$ & $-5.2 \pm 0.1$ & $-4.3 \pm 0.5$ & $-4.8 \pm 0.4$ \\
$\mathrm{NH}_{4}{ }^{+}$ & $-5.6 \pm 0.3$ & $-5.5 \pm 0.4$ & $-4.6 \pm 0.4$ & $-5.2 \pm 0.2$ \\
$\mathrm{~K}^{+}$ & $-5.9 \pm 0.2$ & $-5.8 \pm 0.3$ & $-4.8 \pm 0.1$ & $-4.6 \pm 0.5$ \\
$\mathrm{Na}^{+}$ & $-6.1 \pm 0.1$ & $-5.7 \pm 0.9$ & $-5.3 \pm 0.3$ & $-5.6 \pm 0.2$ \\
$\mathrm{Ca}^{2+}$ & $-6.4 \pm 0.2$ & $-6.6 \pm 0.1$ & $-5.4 \pm 0.6$ & $-5.5 \pm 0.1$ \\
\hline
\end{tabular}

Average of 3 measurements.

\subsection{Impedance and Chronopotentiometric Measurements}

Impedance and chronopotentiometric measurements were carried out to evaluate the performance of MWCNT transducers in the presented solid-contact ISEs. The impedance spectra of MIP (IPU)/MWCNTs-ISEs, MIP (IPU)-CWE, MIP (DU)/MWCNTs-ISEs, and MIP (DU)-CWE are shown in Figure 8. Large semicircles in the high-frequency region were obtained. These are related to the membrane's bulk resistance. It was noticed that the diameter of the obtained semicircles decreased from 0.27 to $0.14 \mathrm{M} \Omega$ and from 0.36 to $0.15 \mathrm{M} \Omega$ after the insertion of MWCNTs, i.e., from MIP (IPU)/MWCNTs-ISEs to MIP (IPU)-CWE and from MIP (DU)/MWCNTs-ISEs to MIP (DU)-CWE, respectively. The contact resistance decreased after the addition of the MWCNT layer. In addition, the charge transfer at the solid-contact interface also improved [50]. At the low-frequency region, a large semicircle was noticed with both the MIP (IPU)-CWE and MIP (IPU)-CWE but none with the MIP (IPU)/MWCNTs-ISEs and MIP (DU)/MWCNTs-ISEs. This is due to the presence of a small double-layer capacitance and large transfer resistance at the interface between the ISM and the GC substrate in the electrodes with no MWCNT films. MWCNT film acts as an ion-to-electron transducer that increases the interface contact capacitance and greatly promotes the ion-electron transfer process.
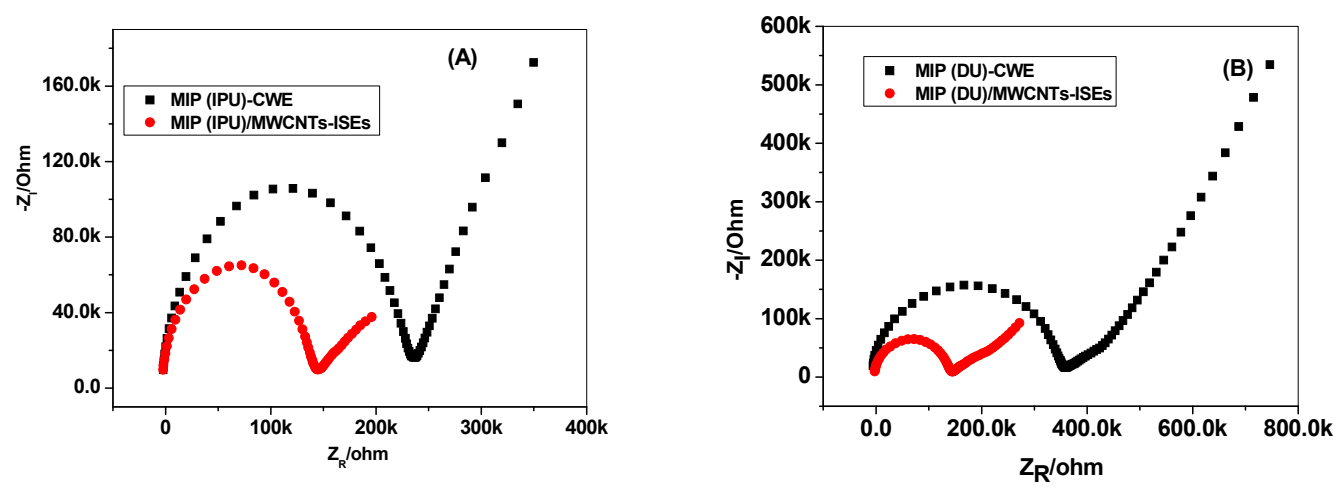

Figure 8. (A) Impedance plots of MIP (IPU)/MWCNTs-ISEs (red) and MIP (IPU)-coated-wire electrodes (CWEs) (black) in the $10^{-4} \mathrm{M}$ IPU solution. (B) Impedance plots of MIP (DU)/MWCNTs-ISEs (red) and MIP (DU)-CWE (black) in the $10^{-4} \mathrm{M}$ DU solution. Conditions: the frequency ranges from $100 \mathrm{kHz}$ to $0.01 \mathrm{~Hz}$ and the disturbance amplitude is $10 \mathrm{mV}$. 
To evaluate the double-layer capacitance of the MWCNTs transducer, which is related to the potential stability of the electrode, chronopotentiometric measurements were carried according to the protocol suggested by Bobacka [50]. The measurements were carried out after applying a $\pm 1 \mathrm{nA}$ current through a controlled three-electrode cell composed of the working electrode, a single-junction $\mathrm{Ag} / \mathrm{AgCl} / \mathrm{KCl}(1 \mathrm{M})$ reference electrode, and $\mathrm{Pt}$ wire as an auxiliary electrode. All were immersed in $10^{-4} \mathrm{M}$ of the herbicide solution.

Chronopotentiometric plots for all the presented sensors are shown in Figure 9. The short-term potential stability for each electrode was evaluated from the slope $(\Delta \mathrm{E} / \Delta \mathrm{t})$ of the $E-T$ curve at longer times. The potential drift for MIP (IPU)/MWCNTs-ISEs, MIP (IPU)-CWE, MIP (DU)/MWCNTs-ISEs, and MIP (DU)-CWE was found to be 9.42, 103.4, 22.3, and $189.5 \mu \mathrm{V} / \mathrm{s}$, respectively. The interfacial capacitance was also evaluated using the formula $\Delta \mathrm{E} / \Delta \mathrm{t}=\mathrm{i} / \mathrm{C}_{\mathrm{L}}$. The obtained double-layer capacitances for MIP (IPU)/MWCNTs-ISEs, MIP (IPU)-CWE, MIP (DU)/MWCNTs-ISEs, and MIP (DU)-CWE were found to be 106.1, 9.67, 44.8, and $5.29 \mu \mathrm{F}$. The high electric capacity obtained after inserting the MWCNT layer in MIP (IPU)/MWCNTs-ISEs or MIP (DU)/MWCNTs-ISEs plays an essential role in resisting the external current's polarization [51].
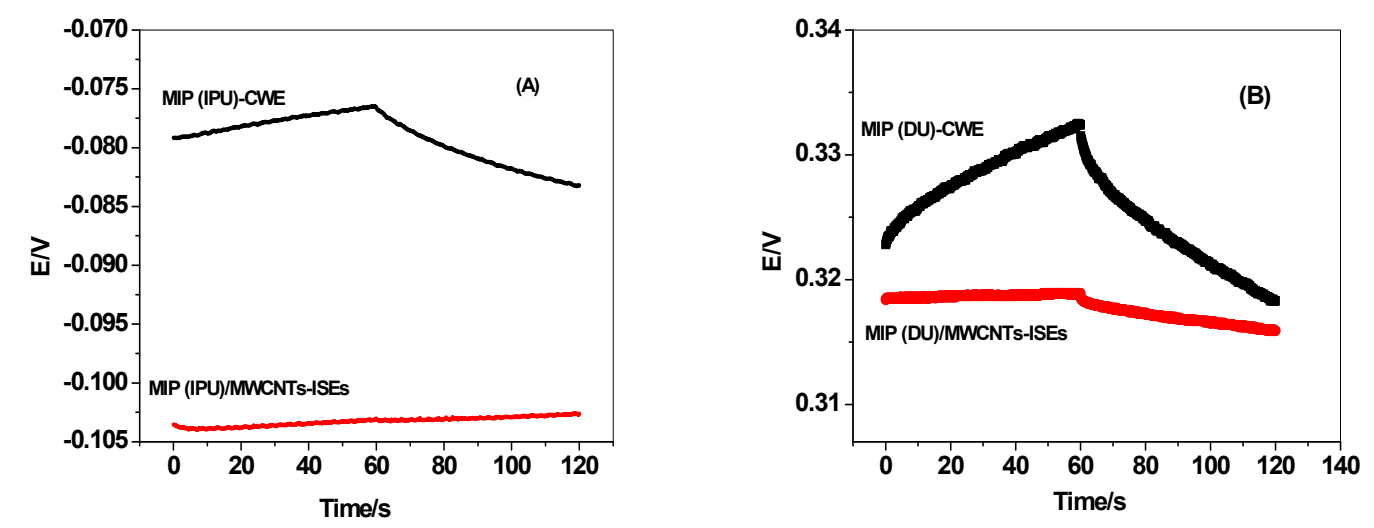

Figure 9. Chronopotentiometric plots of (A) MIP (IPU)/MWCNTs-ISEs (red) and MIP (IPU)-CWE (black) in the $10^{-4} \mathrm{M}$ IPU solution. (B) MIP (DU)/MWCNTs-ISEs (red) and MIP (DU)-CWE (black) in the $10^{-4} \mathrm{M}$ DU solution.

\subsection{Analytical Application: Monitoring of Phenylureas in Water Samples}

To test the applicability of the presented ISEs, they were used to determine IPU and DU herbicides in different wastewater samples collected from different agricultural sources. The water was mixed and spiked with $0.5-10.0 \mu \mathrm{g} / \mathrm{mL}$ phenylureas. The results of the potentiometric analysis conducted in steady-state showed recoveries ranging from 96.8 to $106.1 \%$ and 96.0 to $104 \%$ for MIP (IPU)/MWCNTs-ISEs and MIP (DU)/MWCNTs-ISEs, respectively. As shown in Table 3, the results obtained for the analysis of water samples presented good accuracy and demonstrated the applicability of the sensors for routine analysis without prior separation. 
Table 3. Application of the proposed method to determination of phenylureas in spiked wastewater samples.

\begin{tabular}{cccccc}
\hline \multirow{2}{*}{ Sample } & \multicolumn{4}{c}{ * Concentration of Phenylurea Herbicide, $\mu \mathrm{g} / \mathrm{mL}$} \\
\cline { 2 - 5 } & \multirow{2}{*}{ Amount Added } & \multicolumn{2}{c}{ (IPU)/MWCNTs-ISEs } & \multicolumn{2}{c}{ MIP (DU)/MWCNTs-ISEs } \\
\cline { 3 - 5 } & & Found, IPU & Recovery, $\%$ & Found, DU & Recovery, $\%$ \\
\hline Sample 1 & 0.5 & $0.53 \pm 0.2$ & 106.1 & $0.52 \pm 0.3$ & 104.0 \\
Sample2 & 2.5 & $2.42 \pm 0.4$ & 96.8 & $2.53 \pm 0.2$ & 101.2 \\
Sample3 & 5.0 & $4.87 \pm 0.3$ & 97.4 & $4.93 \pm 0.4$ & 98.6 \\
Sample 4 & 10.0 & $9.7 \pm 0.4$ & 97.0 & $9.6 \pm 0.5$ & 96.0 \\
\hline
\end{tabular}

* Average of 5 measurements.

\section{Conclusions}

A molecular imprinting technique was assigned to design isoproturon (IPU) and diuron (DU) host-tailored sensors for potentiometric transduction. Multiwalled carbon nanotubes (MWCNTs) were employed as ion-to-electron transducers and potassium tetrakis (p-chlorophenyl) borate ( $\mathrm{KTpClB})$ as a lipophilic ionic additive. The sensors revealed a near-Nernstian response for both isoproturon (IPU) and diuron (DU) with slopes of $53.1 \pm 1.2\left(r^{2}=0.997\right)$ and $57.2 \pm 0.3\left(r^{2}=0.998\right)$ over the linear ranges of $2.2 \times 10^{-6}-1.0 \times 10^{-3} \mathrm{M}$ and $3.2 \times 10^{-6}-1.0 \times 10^{-3} \mathrm{M}$ with detection limits of $8.3 \times 10^{-7}$ and $1.4 \times 10^{-6} \mathrm{M}$, respectively. The response time of the presented sensors was found to be $<5 \mathrm{~s}$ and the lifetime was at least eight weeks. Simplicity in design, a short measurement time, good precision, high accuracy, high analytical throughput, and low detection limits were the advantages of these sensors. The sensors exhibited good selectivity towards isoproturon (IPU) and diuron (DU) in comparison with some other herbicides, alkali, alkaline earth, and heavy metal ions. The presented sensors were successfully applied for the direct determination of isoproturon (IPU) and diuron (DU) in real water samples. The proposed method is simple, of low cost, precise, accurate, and inexpensive regarding reagent consumption and the equipment involved.

Author Contributions: A.H.K. and A.E.-G.E.A. gave the concepts of the work, interpretation of the results, the experimental part and prepared the manuscript. A.H.K. performed the revision before submission. M.A.A.-O. and A.A.A. revealed the financial support for the work. All authors have read and agreed to the published version of the manuscript.

Funding: The authors are grateful to the Deanship of Scientific Research, King Saud University for funding this work through Research Group Project "RGP-172".

Conflicts of Interest: The authors declare no conflict of interest.

\section{References}

1. Barbash, J.E.; Resek, E.A. Pesticides in Ground Water. Distribution, Trends and Governing Factors; Ann Arbor Press: Chelsea, MI, USA, 1996.

2. Ragsdale, N.N.; Menzer, R.E. Carcinogenicity and Pesticides: Principles, Issues and Relationships; American Chemical Society: Washington, DC, USA, 1989.

3. Lewis, R.J. Sax's Dangerous Properties of Industrial Materials, 9th ed.; Van Nostrand Reinhold: New York, NY, USA, 1992.

4. Krieger, R. Hayes' Handbook of Pesticide Toxicology, 3rd ed.; Academic Press Inc.: Cambridge, MA, USA, 2010.

5. Vanraes, P.; Wardenier, N.; Surmont, P.; Lynen, F.; Nikiforov, A.; Van Hulle, S.W.H.; Leys, C.; Bogaerts, A. Analysis of Short-Lived Reactive Species in Plasma-Air-WaterSystems: The Dos and the Do Nots. J. Hazard. Mater. 2018, 354, 180-190. [CrossRef] [PubMed]

6. Starling, M.C.V.; Amorim, C.C.; Leão, M.M.D. Occurrence, control and fate of contaminants of emerging concern in environmental compartments in Brazil. J. Hazard. Mater. 2019, 372, 17-36. [CrossRef] [PubMed]

7. Siisse, H.; Müller, H. Pesticide analysis by micellar electrokinetic capillary chromatography. J. Chromatogr. A 1996, 730, 337-343. [CrossRef] 
8. Sherma, J. Current Status of Pesticide Residue Analysis. J. AOAC Int. 1997, 80, 283-288. [CrossRef]

9. Goger, B.; Kunert, O.; Seger, C.; Rinelli, R.; Winstersteiger, R. Quantification of phenylurea pesticides by HPLC/ECD and photolysis. Electroanalysis 2001, 3, 1335. [CrossRef]

10. Farran, A.; Ruiz, S. Application of solid-phase extraction and micellar electrokinetic capillary chromatography to the study of hydrolytic and photolytic degradation of phenoxy acid and phenylurea herbicides. J. Chromatogr. A 2004, 1024, 267-274. [CrossRef]

11. Chicharro, M.; Bermejo, E.; Sanchez, A.; Zapardiel, A.; Fernandez-Gutierrez, A.; Arraez, D. Multiresidue analysis of phenylurea herbicides in environmental waters by capillary electrophoresis using electrochemical detection. Anal. Bioanal. Chem. 2005, 382, 519. [CrossRef]

12. Su, M.; Jia, L.; Wu, X.; Sun, H. Residue investigation of some phenylureas and tebuthiuron herbicides in vegetables by ultra-performance liquid chromatography coupled with integrated selective accelerated solvent extraction-clean up in situ. J. Sci. Food Agric. 2018, 98, 4845-4853. [CrossRef]

13. Gupta, V.; Sethi, B.; Sharma, R.; Agarwal, S.; Bharti, A. Mercury selective potentiometric sensor based on low rim functionalized thiacalix [4]-arene as a cationic receptor. J. Mol. Liq. 2013, 177, 114-118. [CrossRef]

14. Duarte, E.H.; Casarin, J.; Sartori, E.R.; Tarley, C.R.T. Highly improved simultaneous herbicides determination in water samples by differential pulse voltammetry using boron-doped diamond electrode and solid phase extraction on cross-linked poly(vinylimidazole). Sens. Actuators B Chem. 2018, 255, 166-175. [CrossRef]

15. Noyrod, P.; Chailapakul, O.; Wonsawat, W.; Chuanuawatanakul, S. Sensitive simultaneous voltammetric determination of the herbicides diuron and isoproturon at a platinum/chitosan bio-based sensing platform. J. Electroanal. Chem. 2018, 719, 54-59. [CrossRef]

16. Mani, V.; Devasenathipathy, R.; Chen, S.-M.; Wu, T.-Y.; Kohilarani, K. High-performance electrochemical amperometric sensors for the sensitive determination of phenyl urea herbicides diuron and fenuron. Ionics 2015, 21, 2675-2683. [CrossRef]

17. Morawski, F.D.M.; Winiarski, J.P.; De Campos, C.E.M.; Parize, A.L.; Jost, C.L. Sensitive simultaneous voltammetric determination of the herbicides diuron and isoproturon at a platinum/chitosan bio-based sensing platform. Ecotoxicol. Environ. Saf. 2020, 206, 111181. [CrossRef] [PubMed]

18. Sadriu, I.; Bouden, S.; Nicolle, J.; Podvorica, F.; Bertagna, V.; Berho, C.; Amalric, L.; Vautrin-Ul, C. Molecularly imprinted polymer modified glassy carbon electrodes for the electrochemical analysis of isoproturon in water. Talanta 2020, 207, 120222. [CrossRef] [PubMed]

19. Dimeski, G.; Badrick, T.; John, A.S. Ion Selective Electrodes (ISEs) and interferences-A review. Clin. Chim. Acta 2010, 411, 309-317. [CrossRef]

20. Ashmawy, N.H.; Almehizia, A.A.; Youssef, T.A.; El-Galil, E.A.A.; Al-Omar, M.A.; Kamel, A.H. Novel Carbon/PEDOT/PSS-Based screen-printed biosensors for acetylcholine neurotransmitter and acetylcholinesterase detection in human serum. Molecules 2019, 24, 1539. [CrossRef]

21. Hassan, S.S.M.; Elnemma, E.M.; Mohamed, A.H.K. Novel Biomedical Sensors for Flow Injection Potentiometric Determination of Creatinine in Human Serum. Electroanalysis 2005, 17, 2246-2253. [CrossRef]

22. Kamel, A.H.; Amr, A.E.; Galal, H.R.; Al-Omar, M.A.; Almehizia, A.A. Screen-Printed Sensor Based on Potentiometric Transduction for Free Bilirubin Detection as a Biomarker for Hyperbilirubinemia Diagnosis. Chemosensors 2020, 8, 86. [CrossRef]

23. Abd-Rabboh, H.S.M.; Kamel, A.H.; Amr, A.E. Article All-Solid-State Calcium Sensors Modified with Polypyrrol (PPY) and Graphene Oxide (GO) as Solid-Contact Ion-to-Electron Transducers. Chemosensors 2020, 8, 93. [CrossRef]

24. Eldin, A.G.; Amr, A.E.-G.E.; Kamel, A.H.; Hassan, S.S.M. Screen-printed Microsensors Using Polyoctyl-thiophene (POT) Conducting Polymer as Solid Transducer for Ultratrace Determination of Azides. Molecules 2019, 24, 1392. [CrossRef] [PubMed]

25. Van De Velde, L.; D'Angremont, E.; Olthuis, W. Solid contact potassium selective electrodes for biomedical applications-A review. Talanta 2016, 160, 56-65. [CrossRef]

26. Hauser, P.C.; Chiang, D.W.; Wright, G.A. A potassium-ion selective electrode with valinomycin based poly(vinyl chloride) membrane and a poly(vinyl ferrocene) solid contact. Anal. Chim. Acta 1995, 302, 241-248. [CrossRef]

27. Guziński, M.; Lisak, G.; Sokalski, T.; Bobacka, J.; Ivaska, A.; Bocheńska, M.; Lewenstam, A. Solid contact Ion-selective electrodes with highly selective thioamide derivatives of p-tetr-butylcalix[4]arene for the determination of lead(II) in environmental samples. Anal. Chem. 2013, 85, 1555-1561. [CrossRef] [PubMed] 
28. Lindfors, T. Light sensitivity and potential stability of electrically conducting polymers commonly used in solid contact ion-selective electrodes. J. Solid State Electrochem. 2008, 13, 77-89. [CrossRef]

29. Bobacka, J.; Ivaska, A.; Lewenstam, A. Potentiometric Ion Sensors. Chem. Rev. 2008, 108, 329-351. [CrossRef] [PubMed]

30. Mirata, F.; Resmini, M. Molecularly Imprinted Polymers for Catalysis and Synthesis, Molecularly Imprinted Polymers in Biotechnology; Springer: Berlin/Heidelberg, Germany, 2015; pp. 107-129.

31. Lok, C.; Son, R. Application of molecularly imprinted polymers in food sample analysis-A perspective. Int. Food Res. J. 2009, 16, 127-140.

32. Abdalla, N.S.; Amr, A.E.-G.E.; El-Tantawy, A.S.M.; Al-Omar, M.A.; Kamel, A.H.; Khalifa, N.M. Tailor-Made Specific Recognition of Cyromazine Pesticide Integrated in a Potentiometric Strip Cell for Environmental and Food Analysis. Polymers 2019, 11, 1526. [CrossRef] [PubMed]

33. Chen, G.; Jin, M.; Du, P.-F.; Zhang, C.; Cui, X.; Zhang, Y.; She, Y.; Shao, H.; Jin, F.; Wang, S.; et al. A sensitive chemiluminescence enzyme immunoassay based on molecularly imprinted polymers solid-phase extraction of parathion. Anal. Biochem. 2017, 530, 87-93. [CrossRef]

34. Azodi-Deilami, S.; Abdouss, M.; Kordestani, D. Synthesis and Characterization of the Magnetic Molecularly Imprinted Polymer Nanoparticles Using N, N-bis Methacryloyl Ethylenediamine as a New Cross-linking Agent for Controlled Release of Meloxicam. Appl. Biochem. Biotechnol. 2014, 172, 3271-3286. [CrossRef]

35. Asadi, E.; Azodi-Deilami, S.; Abdouss, M.; Khaghani, S. Cyproterone Synthesis, Recognition and Controlled Release by Molecularly Imprinted Nanoparticle. Appl. Biochem. Biotechnol. 2012, 167, 2076-2087. [CrossRef]

36. Haupt, K. Molecularly imprinted polymers in analytical chemistry. Analyst 2001, 126, 747-756. [CrossRef] [PubMed]

37. Ye, L.; Haupt, K. Molecularly imprinted polymers as antibody and receptor mimics for assays, sensors and drug discovery. Anal. Bioanal. Chem. 2004, 378, 1887-1897. [CrossRef] [PubMed]

38. Li, H.-H.; Wang, H.-H.; Li, W.-T.; Fang, X.-X.; Guo, X.-C.; Zhou, W.-H.; Cao, X.; Kou, D.-X.; Zhou, Z.-J.; $\mathrm{Wu}, \mathrm{S} . \mathrm{X}$. A novel electrochemical sensor for epinephrine based on three dimensional molecularly imprinted polymer arrays. Sens. Actuators B Chem. 2016, 222, 1127-1133. [CrossRef]

39. Chen, H.; Zhang, W.; Yang, N. Chitosan-Based Surface Molecularly Imprinted Polymer Microspheres for Sustained Release of Sinomenine Hydrochloride in Aqueous Media. Appl. Biochem. Biotechnol. 2017, 185, 370-384. [CrossRef] [PubMed]

40. Li, S.; Tao, H.; Li, J. Molecularly Imprinted Electrochemical Luminescence Sensor Based on Enzymatic Amplification for Ultratrace Isoproturon Determination. Electroanalysis 2012, 24, 1664-1670. [CrossRef]

41. Kamel, A.H.; Jiang, X.; Li, P.; Liang, R. A paper-based potentiometric sensing platform based on molecularly imprinted nanobeads for determination of bisphenol A. Anal. Methods 2018, 10, 3890-3895. [CrossRef]

42. El-Kosasy, A.; Kamel, A.H.; Hussin, L.; Ayad, M.F.; Fares, N. Mimicking new receptors based on molecular imprinting and their application to potentiometric assessment of 2,4-dichlorophenol as a food taint. Food Chem. 2018, 250, 188-196. [CrossRef]

43. Kamel, A.H. Solid Contact Potentiometric Sensors Based on Host-Tailored Molecularly Imprinted Polymers for Creatine Assessment. Int. J. Electrochem. Sci. 2016, 11, 8938-8949. [CrossRef]

44. Hassan, S.S.M.; Amr, A.E.-G.E.; El-Naby, H.A.; Al-Omar, M.A.; Kamel, A.H. Non-Equilibrium Potential Responses towards Neutral Orcinol Using All-Solid-State Potentiometric Sensors Integrated with Molecularly Imprinted Polymers. Polymers 2019, 11, 1232. [CrossRef]

45. Abd-Rabboh, H.S.M.; Kamel, A.H. Mimicking a Receptor for Cyanide Ion Based on Ion Imprinting and Its Applications in Potential Transduction. Electroanalysis 2012, 24, 1409-1415. [CrossRef]

46. Moreira, F.T.; Guerreiro, J.R.L.; Azevedo, V.L.; Kamel, A.H.; Sales, M.G.F. New biomimetic sensors for the determination of tetracycline in biological samples: Batch and flow mode operations. Anal. Methods 2010, 2, 2039. [CrossRef]

47. Yamamura, H.L.; Enna, S.J.; Kuhar, M.J. Neurotransmitter Receptor Binding; Raven Press: New York, NY, USA, 1985.

48. Taylor, J.K. Quality Assurance of Chemical Measurements; CRC Press: Boca Raton, FL, USA, 1987.

49. Bakker, E.; Pretsch, E.; Bühlmann, P. Selectivity of potentiometric ion sensors. Anal. Chem. 2000, 72, 1127-1133. [CrossRef] [PubMed] 
50. Konopka, A.; Sokalski, T.; Michalska, A.; Lewenstam, A.; Maj-Żurawska, M. Factors Affecting the Potentiometric Response of All-Solid-State Solvent Polymeric Membrane Calcium-Selective Electrode for Low-Level Measurements. Anal. Chem. 2004, 76, 6410-6418. [CrossRef] [PubMed]

51. Bobacka, J. Potential Stability of All-Solid-State Ion-Selective Electrodes Using Conducting Polymers as Ion-to-Electron Transducers. Anal. Chem. 1999, 71, 4932-4937. [CrossRef]

(C) 2020 by the authors. Licensee MDPI, Basel, Switzerland. This article is an open access article distributed under the terms and conditions of the Creative Commons Attribution (CC BY) license (http://creativecommons.org/licenses/by/4.0/). 